\title{
Case Studies of Easterly Wave Disturbances over Northeast Brazil Using the Eta Model
}

\author{
ROgER RODRIGUES TORRES AND NELSON JESUS FERREIRA \\ Center for Weather Forecast and Climate Studies/National Institute for Space Research, CPTEC/INPE, São José dos Campos, \\ São Paulo, Brazil
}

(Manuscript received 24 March 2010, in final form 29 September 2010)

\begin{abstract}
This research aims to analyze two easterly wave disturbance events that reached the east coast of Northeast Brazil (NEB) on 15 May 2005 and 20 June 2006. The performance of the regional Eta Model was evaluated through four sets of experiments using different horizontal resolutions $(10$ and $40 \mathrm{~km})$ and convective parameterization schemes [Betts-Miller-Janjić (BMJ) and Kain-Fritsch (KF)]. Through analysis of 700-hPa wind fields, all experiments, with 40- and 10-km horizontal resolutions and using the BMJ and KF schemes, were shown to well represent a trough propagating westward from about $20^{\circ} \mathrm{W}$ to NEB, with a 5-day forecast range. When evaluating the model sensitivity to different convective parameterizations, all the experiments showed similar results and underestimated rainfall in most of the domain. The obtained results suggest the need to extend this analysis to a larger number of cases and to test other cumulus parameterizations in order to improve the rainfall forecast in eastern NEB.
\end{abstract}

\section{Introduction}

Northeast Brazil (NEB) has a total area of about 1.5 million $\mathrm{km}^{2}$ and a population of approximately 52 million inhabitants. Most of this region has a semiarid climate, due to the prevailing rainfall regime. However, while portions of the inland dry regions receive less than $600 \mathrm{~mm}$ of rainfall annually, the east coast receives around $2000 \mathrm{~mm}$ (Kousky and Chu 1978; Rao et al. 1993).

It is possible to identify different rainfall patterns in NEB. In the northern part of this region, the main rainy season occurs from March to April; in the south, the rainy season is observed from December to February, and on the east coast it occurs from May to July (Strang 1972; Rao et al. 1993). Moreover, there are regions with superimposed periods of maximum rainfall, such as the central and northeastern parts of the state of Bahia, where the maximum observed rainfall occurs from December to March, and the coastal part of Bahia, where the maximum occurs from December to May (Strang 1972; Kousky and Chu 1978). The spatial variability of annual rainfall is also high in NEB (Rao et al. 1993). The maximum rainfall amount observed during the March-April period in

Corresponding author address: Roger Rodrigues Torres, National Institute for Space Research, Cachoeira Paulista, São Paulo, Brazil.

E-mail: roger.torres@cptec.inpe.br northern NEB can be attributed to the latitudinal displacement of the intertropical convergence zone (ITCZ), which reaches its southernmost position during these months (Hastenrath and Heller 1977). The observed maximum during November-December in the southern part of the region can be attributed to frontal systems that reach low latitudes and interact with convective activity from the Amazon Basin or from the northern coast of Brazil (Kousky 1979).

Several attempts have been made to explain the rainfall maximum in autumn and winter along the east coast of NEB. Yamazaki and Rao (1977) emphasized the importance of westward-propagating cloud systems, as detected in satellite images over the Atlantic Ocean. Kousky (1979) showed that rainfall in eastern NEB is influenced by breeze circulations, mainly during the night. Kousky attributed the nocturnal maximum to the formation of a convergence zone between the land breeze and the background wind field. He also noted that the land breeze is strongest during autumn and winter, when the temperature contrast between land and sea is higher than normal. Studies such as Rao et al. (1993) indicate that the position and intensity of the South Atlantic subtropical high is an important mechanism for the low-level transport of water vapor toward NEB. Ferreira et al. (1990) identified the occurrence of easterly wave disturbances (EWDs) in the wind field, which propagated westward over the tropical South Atlantic Ocean during the austral autumn and 
TABLE 1. Design of experiments using the Eta Model.

\begin{tabular}{cccc}
\hline \hline Simulation & $\begin{array}{c}\text { Resolution } \\
(\mathrm{km})\end{array}$ & $\begin{array}{c}\text { Convective } \\
\text { parameterization }\end{array}$ & $\begin{array}{c}\text { Adopted } \\
\text { terminology }\end{array}$ \\
\hline 1 & 40 & BMJ & BMJ40 \\
2 & 10 & BMJ & BMJ10 \\
3 & 40 & KF & KF40 \\
4 & 10 & KF & KF10 \\
\hline
\end{tabular}

winter. When these disturbances interact with local circulations, low-level convergence increases, causing strong rainfall on the eastern and northern NEB coasts.

Although EWDs occur in several tropical regions, they are more frequently observed in the Northern Hemisphere. Therefore, more attention has been given to the regions of the western Pacific Ocean, the Caribbean Sea, West Africa, and the eastern Atlantic Ocean (Yanai et al. 1968; Yanai and Nita 1967; Reed and Recker 1971; Albignat and Reed 1980; Thorncroft 1995; Paradis et al. 1995; Hsieh and Cook 2005; Chen 2006; Berry et al. 2007; among others). A few studies have focused on the South Atlantic tropical region, near the Brazilian coast (Yamazaki and Rao 1977; Kayano 2003; Hall 1989; Ferreira et al. 1990; Coutinho and Fisch 2007).

Despite recent advances in understanding the weather systems that impact NEB, rainfall forecasting over the coastal region is still a difficult task for operational weather services. Frequently, winter rainfall over NEB related to EWDs causes flooding and, consequently, severe social and economic impacts. Although analyses and forecasts from global atmospheric models are helpful tools for EWD identification, their low spatial resolution often does not allow a clear definition of the occurrence of these weather systems and a suitable rainfall amount forecast. Due to these difficulties, the use of regional models is valuable due to their improved spatial resolution and ability to depict local circulations. Therefore, the aim of this study is to evaluate the predictability of EWDs over NEB using the regional Eta Model through the simulation of two typical events that took place on 15 May 2005 and 20 June 2006. In particular, the Eta Model performance using two different spatial resolutions $(10$ and $40 \mathrm{~km})$ and convective parameterization schemes [Betts-Miller-Janjić (BMJ) and Kain-Fritsch $(\mathrm{KF})$ schemes] is evaluated against the observed daily rainfall.

\section{Data and methodology}

The current study analyzes four sets of experiments generated with the Eta Model (Mesinger et al. 1988; Black 1994; Chou et al. 2005), simulating two EWD events that occurred along the NEB east coast and induced heavy rainfall on 15 May 2005 and 20 June 2006.
TABLE 2. Scheme of conducted simulation runs ( \pm days).

\begin{tabular}{|c|c|c|c|c|c|c|c|c|c|c|c|c|}
\hline & & -5 & -4 & -3 & -2 & -1 & $\begin{array}{c}\text { Even } \\
\text { day }\end{array}$ & +1 & +2 & +3 & +4 & +5 \\
\hline Initial & $D-1$ & & & & & $X$ & $\mathbf{X}$ & $\mathrm{X}$ & $\mathrm{X}$ & $\mathrm{X}$ & $\mathrm{X}$ & $X$ \\
\hline \multirow[t]{4}{*}{ time } & $D-2$ & & & & X & X & $\mathbf{X}$ & X & X & X & X & \\
\hline & $D-3$ & & & $\mathrm{X}$ & $\mathrm{X}$ & $\mathrm{X}$ & $\mathbf{X}$ & $X$ & $\mathrm{X}$ & $\mathrm{X}$ & & \\
\hline & $D-4$ & & $\mathrm{X}$ & $X$ & $X$ & $X$ & $\mathbf{X}$ & $\mathrm{X}$ & $\mathrm{X}$ & & & \\
\hline & $D-5$ & $\mathrm{X}$ & $\mathrm{X}$ & $\mathrm{X}$ & $X$ & $X$ & $\mathbf{X}$ & $\mathrm{X}$ & & & & \\
\hline
\end{tabular}

The Eta Model version used in this study is the same one used for operational weather forecasting at the Center for Weather Forecast and Climate Studies/National Institute for Space Research [CPTEC/INPE (from its acronym in Portuguese); Chou et al. 2005]. This model uses National Centers for Environmental Prediction (NCEP) analyses as the initial and boundary conditions.

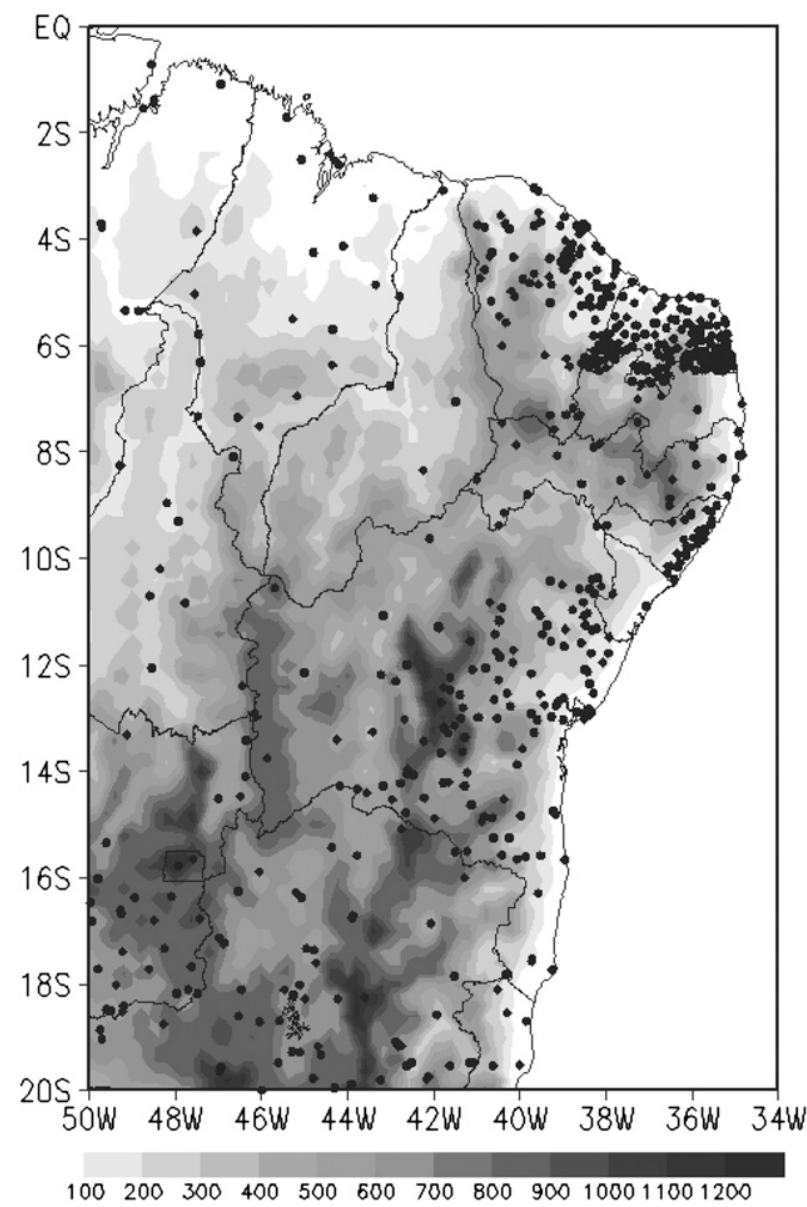

FIG. 1. Spatial distribution of rain gauges from different sources (regional and local agencies and automated stations) over Northeast Brazil provided by the Brazilian National Institute of Meteorology (INMET, its acronym in Portuguese), CPTEC/INPE, and regional meteorological centers. The topography $(\mathrm{m})$ of the region is shaded. 


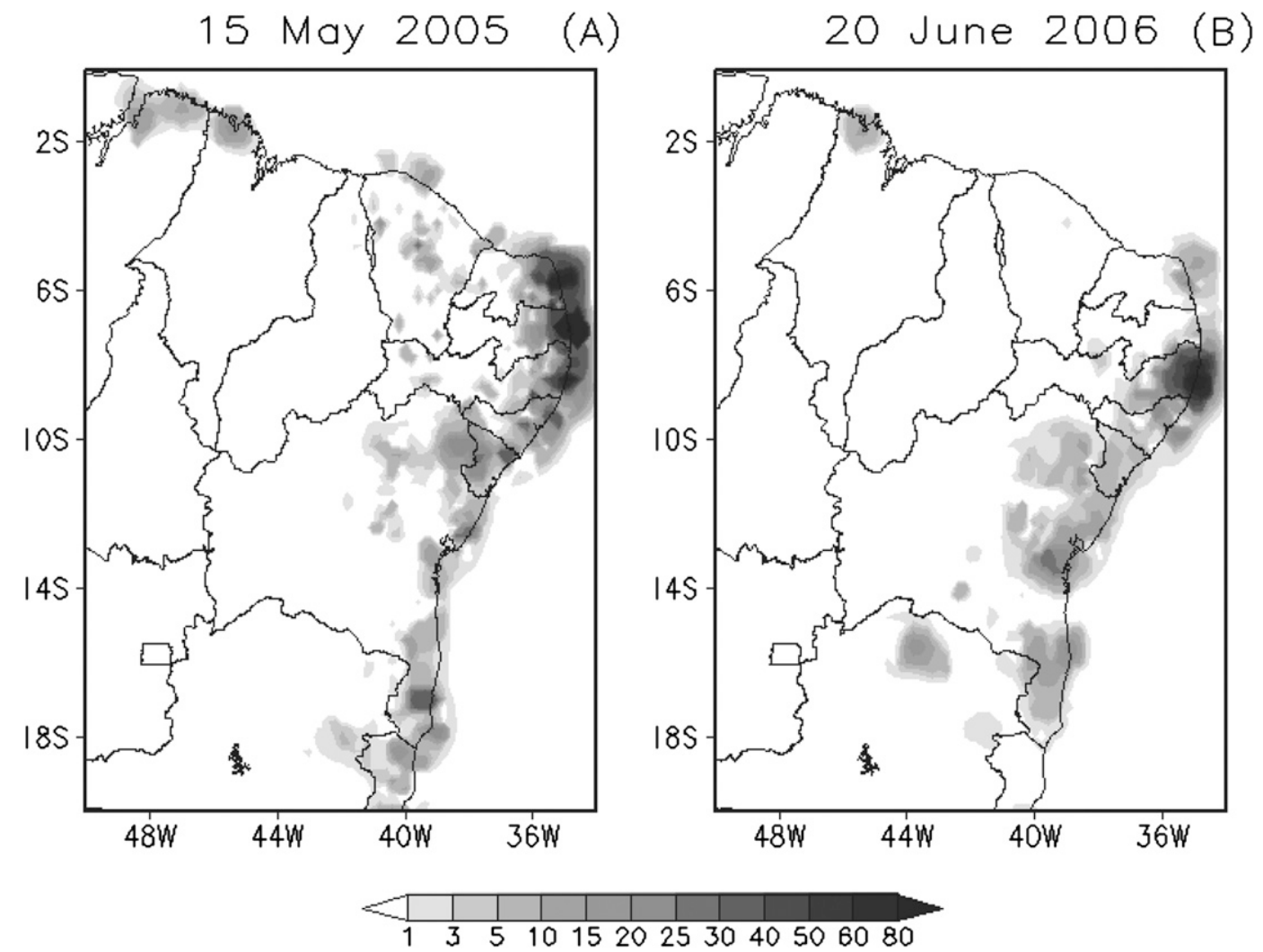

FIG. 2. Observed precipitation amounts (mm) on (a) 15 May 2005 and (b) 20 Jun 2006.

Boundary conditions were modified every $6 \mathrm{~h}$, on the assumption that during these intervals, variable tendencies vary linearly. The data were interpolated vertically to Eta surfaces (Mesinger 1984) and horizontally to the Arakawa E grid (Arakawa and Lamb 1977). Sea surface temperature input data were also modified on a daily basis and the soil moisture and albedo were obtained from monthly and seasonal global climatologies, respectively.

For each simulated event, the model was integrated using two different spatial resolutions (10 and $40 \mathrm{~km}$ ) and convective parameterization schemes (BMJ and KF), as described in Table 1, with the objective of finding the most appropriate configuration to represent the observed rainfall in the analyzed region.

The BMJ scheme is a convective adjustment scheme in which the convective activation is determined using cloudlayer moisture and convective available potential energy (CAPE). The scheme will normally activate convection if CAPE exists for some parcels in the lowest $200 \mathrm{mb}$ of a sounding, although activation may be in the form of shallow convection if the atmosphere is not sufficiently moist over a deep layer. When activated, both modes of convection adjust the gridpoint environment toward a subsaturated, predefined temperature and dewpoint profile
(Betts 1986; Betts and Miller 1986; Janjić 1994; Kain et al. 2001; Baldwin et al. 2002).

The KF scheme is a mass-flux scheme that uses a simple cloud model to portray the vertical redistribution of mass in a column. When parcels originating in the lower troposphere are able to reach their level of free convection (LFC) and continue to rise for some specified depth $(\sim 4 \mathrm{~km})$, deep convection is activated. If a parcel reaches its LFC but does not continue to rise high enough for deep convection to activate, shallow convection is activated. Convective adjustment in the KF scheme does not adjust the modeled atmosphere to specific profiles; instead, simple models of updrafts, downdrafts, and local compensating vertical motions are used to make adjustments (Kain and Fritsch 1990, 1993; Kain et al. 2001; Kain 2004).

For each simulation described in Table 1, the Eta Model was initialized 5 times, starting 1-5 days before each event $(D-1, D-2, \ldots, D-5$, respectively; see Table 2). The total integration time was $168 \mathrm{~h}$, and the simulation domain was delimited by $0^{\circ}$ and $20^{\circ} \mathrm{S}$ and $9^{\circ} \mathrm{W}$ and $50^{\circ} \mathrm{W}$.

The wind field, moisture divergence, and rainfall patterns simulated by the Eta Model were analyzed. The rainfall was evaluated through comparisons between observed and simulated daily totals. The observed rainfall 


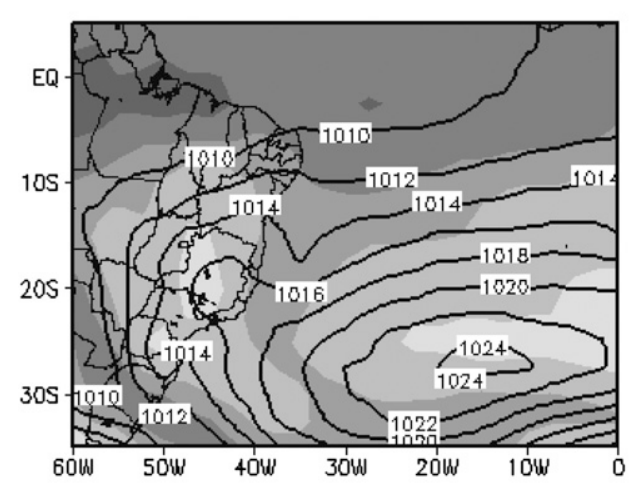

(A)
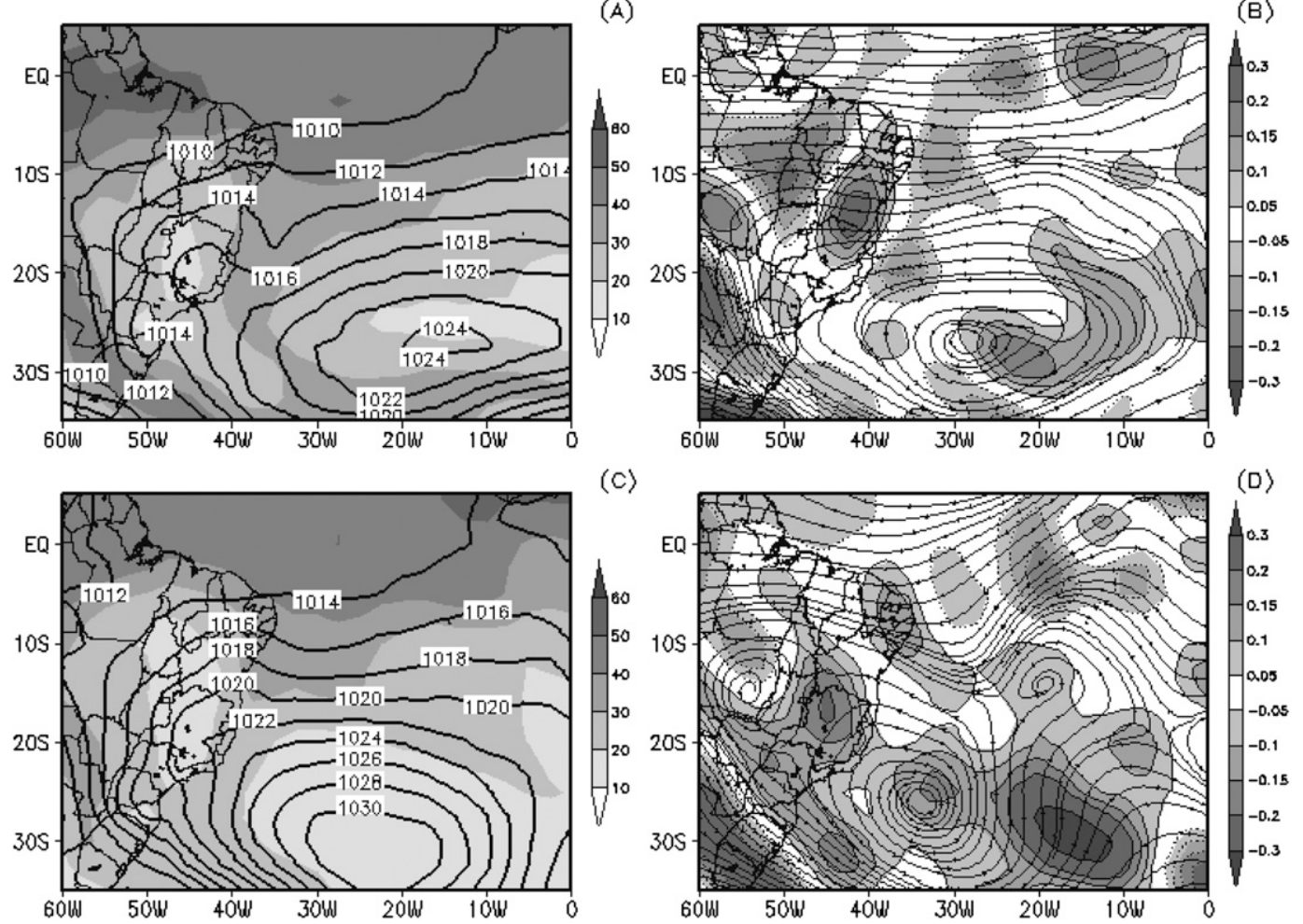

FIG. 3. (a),(c) SLP (hPa) and precipitable water $\left(\mathrm{kg} \mathrm{m}^{-2}\right.$, shaded) and (b),(d) streamlines and omega $\left(\mathrm{Pa} \mathrm{s}^{-1}\right.$, shaded) at $700 \mathrm{hPa}$ on (a),(b) 15 May 2005 and (c),(d) 20 Jun 2006 obtained from the NCEP-NCAR reanalysis. Dotted lines represent negative values.

data employed in these evaluations are derived from Tropical Rainfall Measuring Mission (TRMM) satellite precipitation estimates and surface observations combined with a new technique called MERGE, used to validate all operational models at CPTEC/INPE since July 2008 (Rozante et al. 2010). Figure 1 shows the spatial distribution of rain gauges over northeast Brazil, as well as the topography of the region. Synoptic-scale meteorological conditions were obtained from NCEP-NCAR reanalysis data (Kalnay et al. 1996).

\section{Results}

The days of 15 May 2005 and 20 June 2006 were characterized by above average rainfall at several locations along the NEB east coast, where these pluviometric indexes were related to EWD (Fig. 2). The largest amounts of total precipitation were observed in Natal $\left(5^{\circ} 47^{\prime} \mathrm{S}\right.$, $\left.35^{\circ} 12^{\prime} \mathrm{W}\right)$ and João Pessoa $\left(7^{\circ} 06^{\prime} \mathrm{S}, 34^{\circ} 51^{\prime} \mathrm{W}\right)$ (164 and $130 \mathrm{~mm}$, respectively) on 15 May 2005, and in Recife $\left(8^{\circ} 03^{\prime} \mathrm{S}, 34^{\circ} 52^{\prime} \mathrm{W}\right)$ and $\mathrm{Natal}$ ( 83 and $39 \mathrm{~mm}$, respectively) on 20 June 2006. During both events, the NCEP-NCAR reanalysis wind fields show a 700-hPa trough supporting instability in that region (Fig. 3). Through analysis of wind fields and meteorological satellite images with a time step of $6 \mathrm{~h}$ (not shown), it was also possible to verify that areas with enhanced convective activity coincided with centers of upward air movement and low-level moisture convergence located east of the trough. In both cases, a trough in the sea level pressure field was associated with a trough in the middle levels, although this was more pronounced during the 15 May 2005 event (Fig. 3a). Also, high values of precipitable water were found during both events along the north and northeast coasts, associated with the ITCZ. During the second event, it was noted that the South Atlantic subtropical high pressure center was more intense and closer to the continent than during the first event, as is characteristic of the transition from May to June (Fig. 3). The intensity and position of this pressure center modulate the influx of moisture to the Brazilian northeast coast.

Figures 4 to 7 show $700-\mathrm{hPa}$ streamlines and moisture divergence patterns for the experiments with initialization times of 48 and $120 \mathrm{~h}(D-2$ and $D-5$, respectively) before the events on 15 May 2005 and 20 June 2006. The terminology used for the simulations is described in Table 1 . The choice of the $D-2$ and $D-5$ experiments is a result of our interest in exploring the potential for EWD identification using the Eta Model. Therefore, the experiments with initialization times of 2 and 5 days 

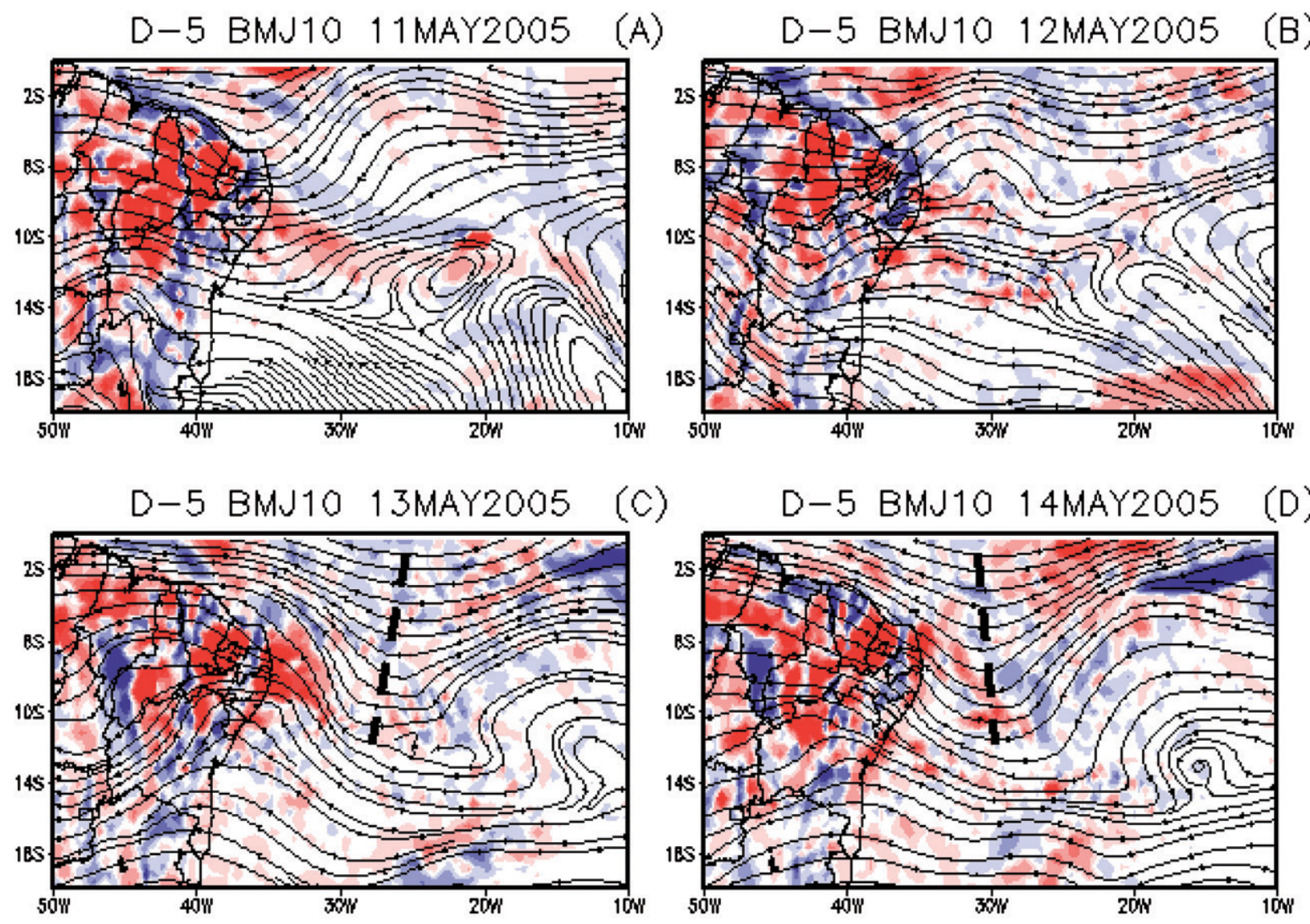

C)
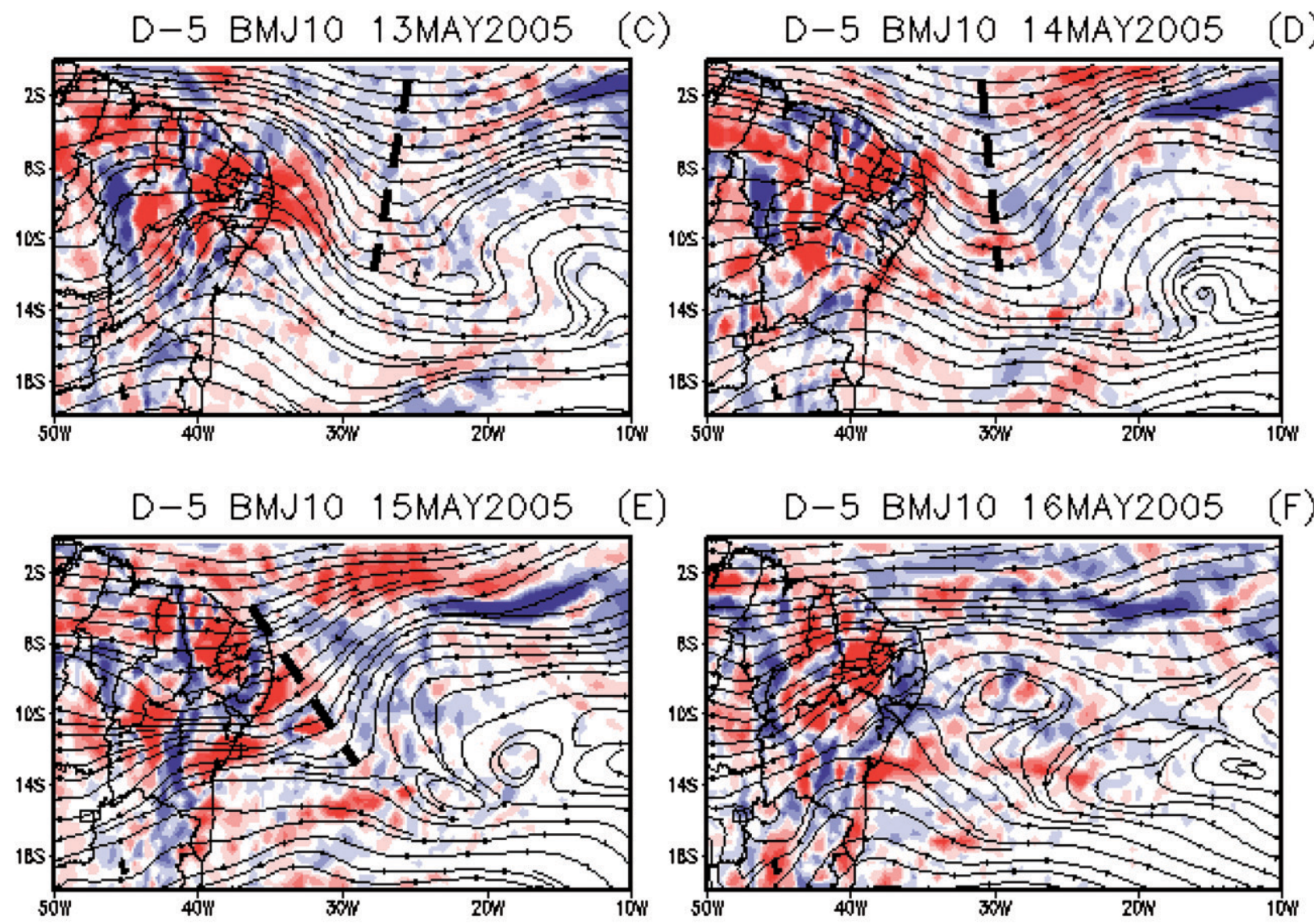

(E)
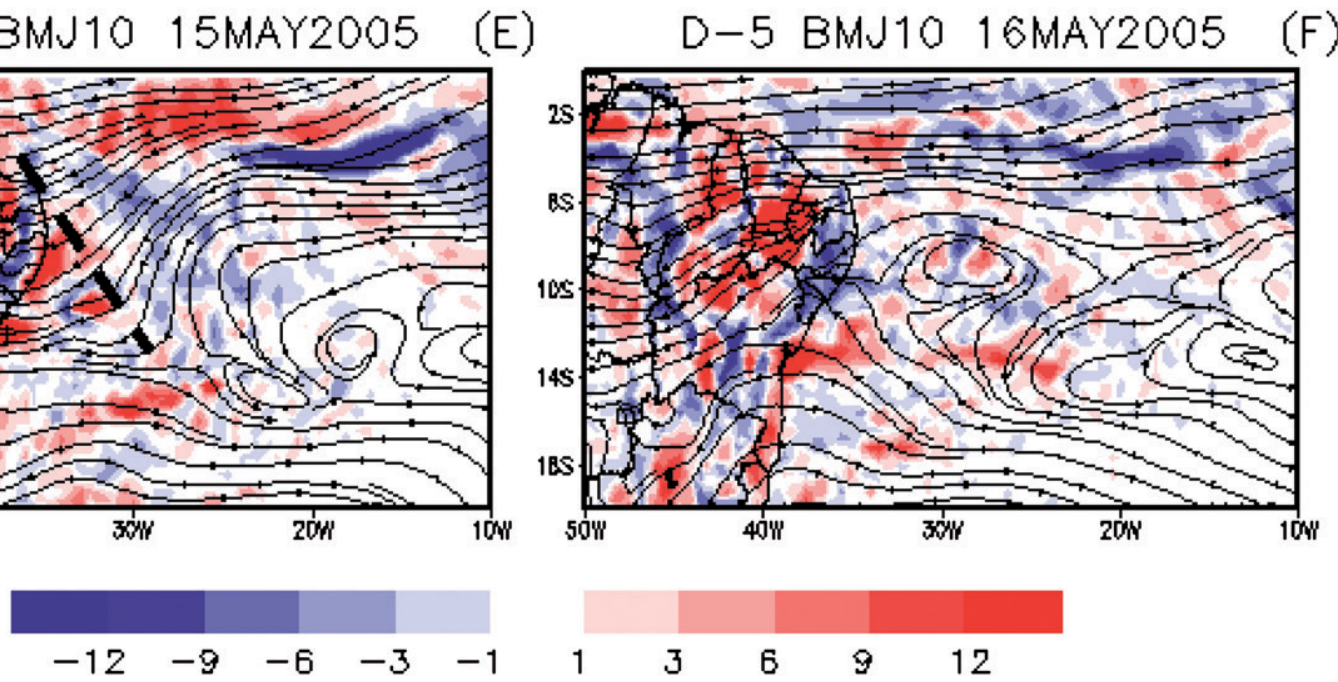

FIG. 4. Daily streamlines and moisture divergence (colors, $10^{-5} \mathrm{~g} \mathrm{~kg}^{-1} \mathrm{~s}^{-1}$ ) at $700 \mathrm{hPa}$ for BMJ10 simulations for (a)-(f) the period from 11 to 16 May 2005, with an initialization time of 5 days before $(D-5)$ the 15 May 2005 event.

before the occurrence of these disturbances were selected. Knowing that during the first $24 \mathrm{~h}$ of integration regional models are strongly influenced by the global model data employed as initial and boundary conditions, experiments beginning at $D-2$ instead of $D-1$ are shown.
Analyzing Figs. 4 and 5, referring to the $D-5$ initialization time of the 15 May 2005 event using the BMJ convective scheme and spatial resolutions of 10 and $40 \mathrm{~km}$, respectively, it is possible to verify that both experiments simulated very well a trough at $700 \mathrm{hPa}$ 

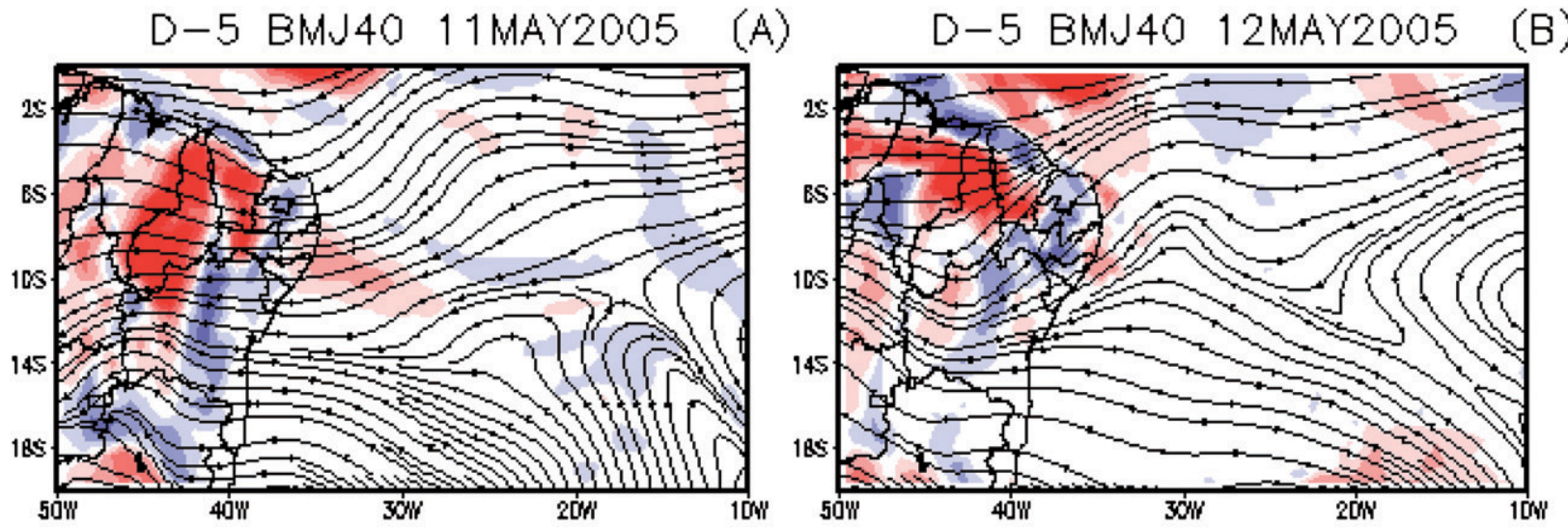

D-5 BMJ40 13MAY2005
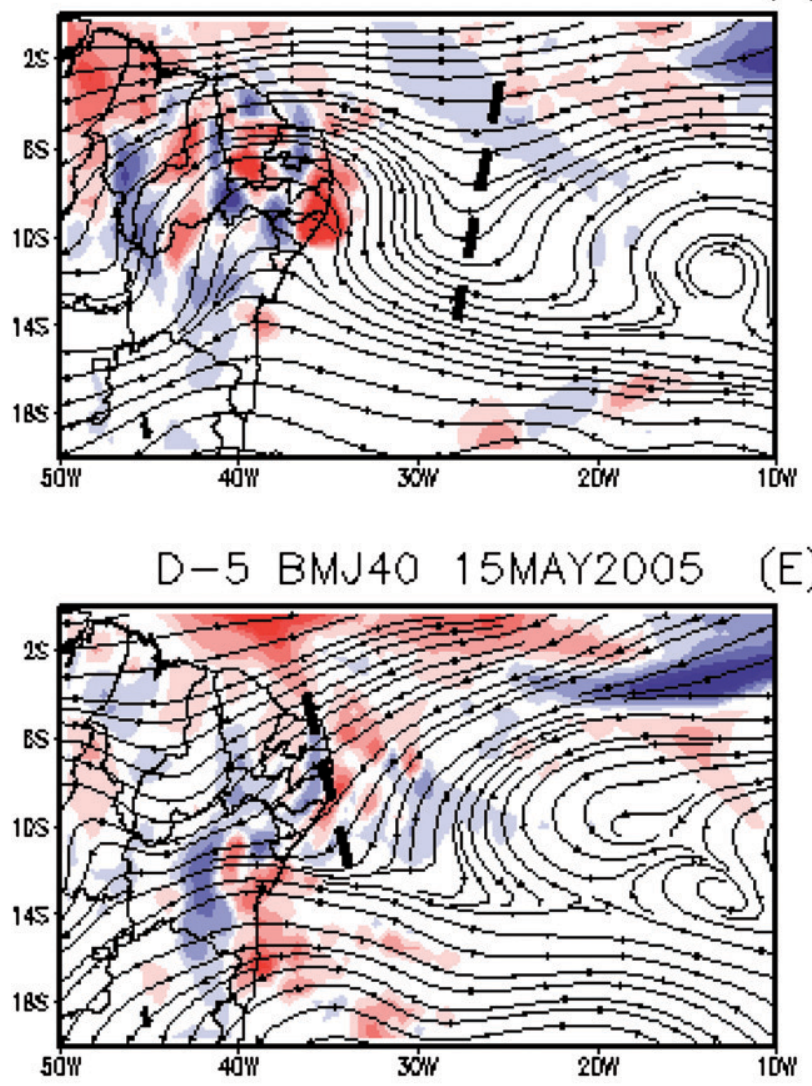

(E)
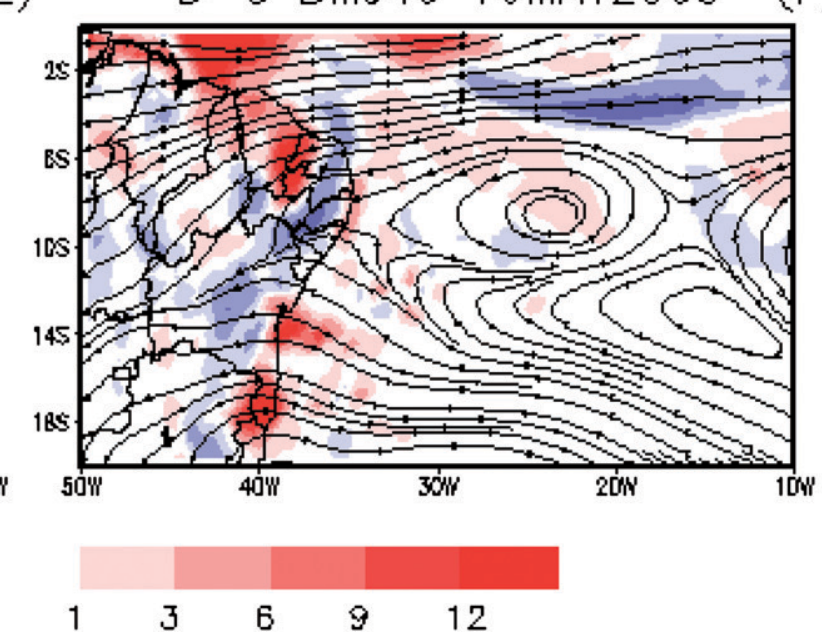

FIG. 5. As in Fig. 4, but for the BMJ40 simulation.

propagating westward from around $20^{\circ} \mathrm{W}$ to the NEB east coast, favoring low-level moisture convergence over the coastal area between $5^{\circ}$ and $10^{\circ} \mathrm{S}$ on 15 and 16 May. The trough started to weaken on 16 May and dissipated during the following days (not shown). With the $D-2$ initialization time (Fig. 6), also using the BMJ scheme, both experiments with 10 - and $40-\mathrm{km}$ spatial resolutions showed quite similar results to the $D-5$ simulations.

The BMJ10 $D-5$ integration for the EWD event that reached NEB on 20 June 2006 is shown in Fig. 7. On 18 June, the model simulated a cyclonic vortex near $20^{\circ} \mathrm{W}$ that subsequently transformed into a trough. As the system 
D-2 BMJ10 14MAY2005

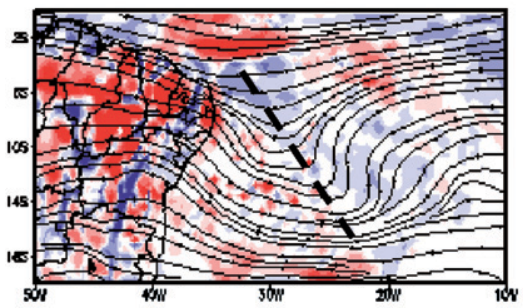

D-2 BMJ40 14MAY2005

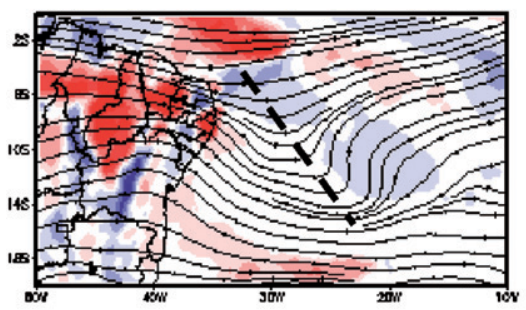

(A)

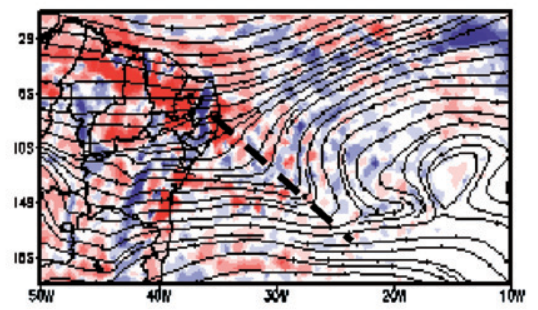

D-2 BMJ40 15MAY2005

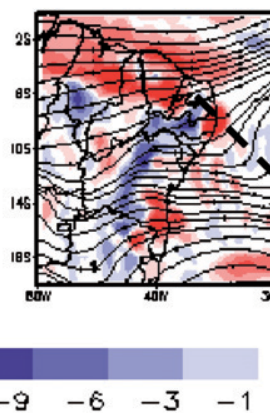

(B)

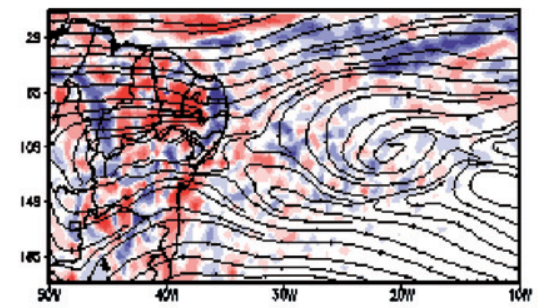

(E)
D-2 BMJ10 16MAY2005

〈C〉
D-2 BMJ40 16MAY2005

(F)
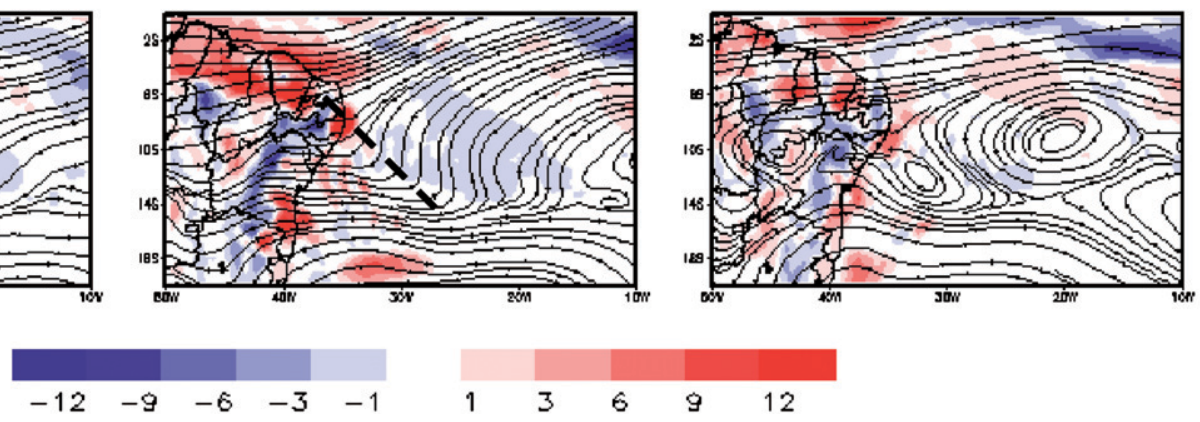

FIG. 6. Daily streamlines and moisture divergence (colors, $10^{-5} \mathrm{~g} \mathrm{~kg}^{-1} \mathrm{~s}^{-1}$ ) at $700 \mathrm{hPa}$ for (a)-(c) BMJ10 and (d)-(f) BMJ40 simulations for the period from 14 to 16 May 2005, with an initialization time of 2 days before $(D-2)$ the 15 May 2005 event.

propagated westward, the trough amplified, reaching NEB on 20 June and favoring low-level moisture convergence over the eastern coastal area. As in the case of the 15 May 2005 event, simulations using 40-km spatial resolution showed comparable results to the $10-\mathrm{km}$ resolution experiments and, so, were omitted here. In the same manner, the $D-2$ simulations again showed results quite similar to the $D-5$ simulations (not shown), which indicates a good possibility of identifying such disturbances 5 days before their occurrence.

In all of our experiments, the choice of convective parameterization did not result in any significant change in the wind field and moisture divergence patterns. For that reason, only experiments using the BMJ parameterization are presented here.

Figures 8 and 9 show the rainfall predictions for 15 May 2005 and 20 June 2006, respectively, produced by all experiments with initialization times of $2(D-2)$ and 5 $(D-5)$ days before each event. Comparing these predictions with the observed daily precipitation (Fig. 2), it is noted that all experiments underestimated or did not adequately predict rainfall in the coastal region. Also, all model runs showed a systematic overestimation of rainfall in the oceanic portion.

The dominance of regions where rainfall was underestimated for the analyzed events can be related to systematic errors in the Eta Model, as suggested by Chou et al. (2005). Evaluating the seasonal precipitation forecasts in South America produced by this model, they found that the worst results were observed in NEB during the winter and spring seasons.

Comparing simulations with different spatial resolutions, a higher resolution did not result in a better precipitation forecast. In fact, for the KF runs, the increase of resolution resulted in a noisier and misplaced precipitation field. The same results are true for the $D-1$, $D-3$, and $D-4$ experiments (not shown).

Figures 8 and 9 also show the corresponding rainfall predictions produced by the Global Forecast System (GFS) model run by NCEP (Kanamitsu 1989; Kanamitsu et al. 1991; Kalnay et al. 1990) with a horizontal resolution of $1^{\circ} \times 1^{\circ}$ latitude-longitude. In the GFS model, convection is parameterized following Pan and Wu (1995), which is based on Arakawa and Schubert (1974) as simplified by Grell (1993). It can be seen that the GFS rainfall prediction, as well as the Eta Model simulations, do not correctly simulate the precipitation that occurred along the NEB east coast. GFS runs put an unrealistic precipitation amount over the ocean and almost no precipitation over land in the two analyzed cases, mainly on 15 May when the more intense event occurred.

Regarding the different initialization times employed, hardly any improvement was observed between the $D-5$ and $D-2$ simulations, although a stronger large-scale forcing is noticeable in the $D-2$ GFS runs. Nevertheless, it is noticeable that the KF runs showed the best results among all experiments for $D-2$ simulations of the 20 June case (Figs. 9a-e). 


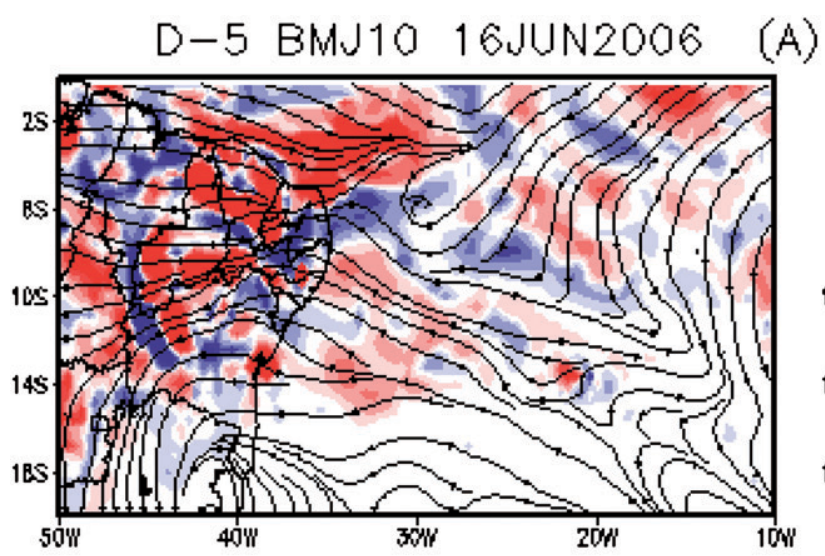

$$
\text { D-5 BMJ10 17JUN2006 }
$$
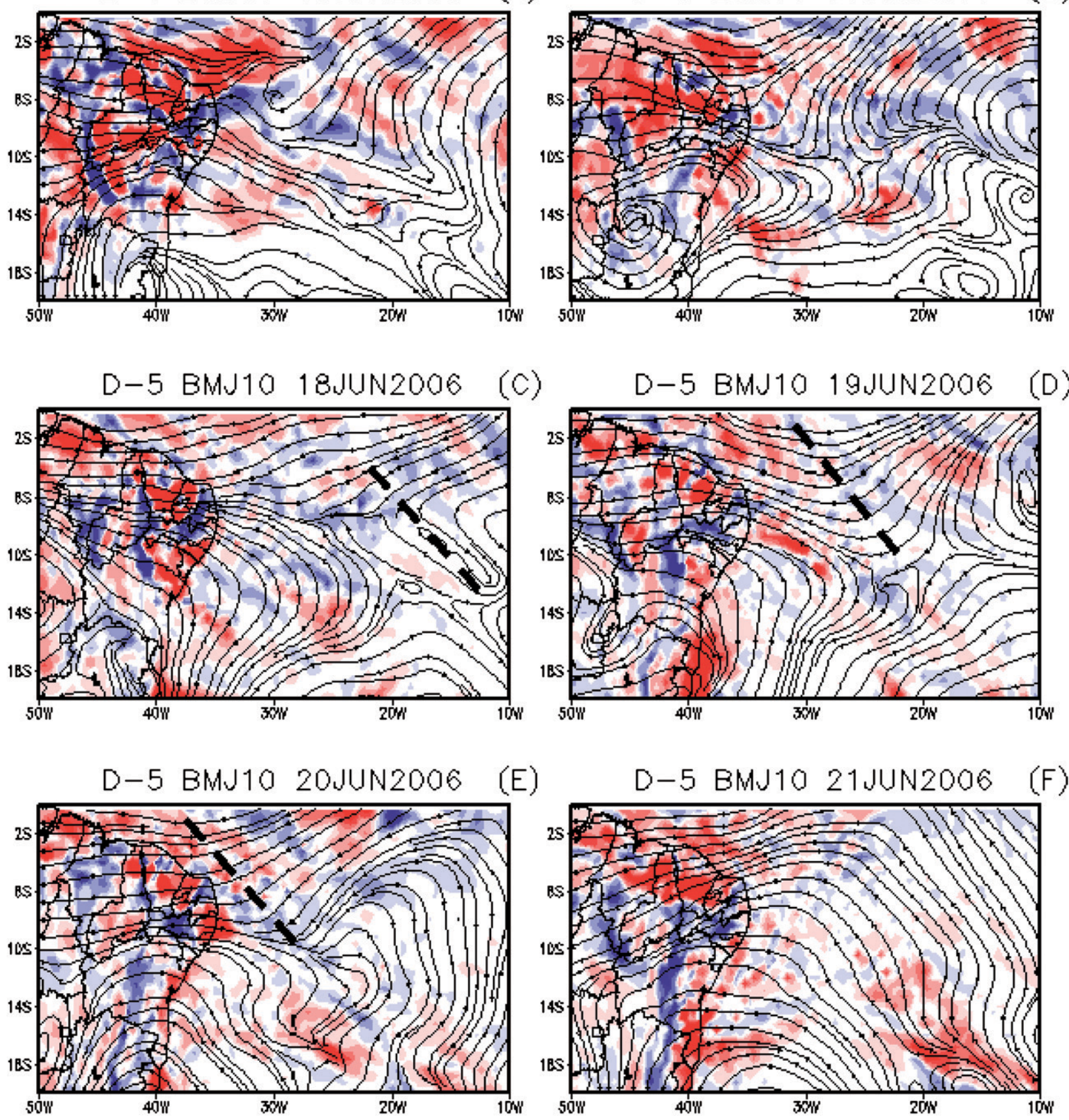

(E)

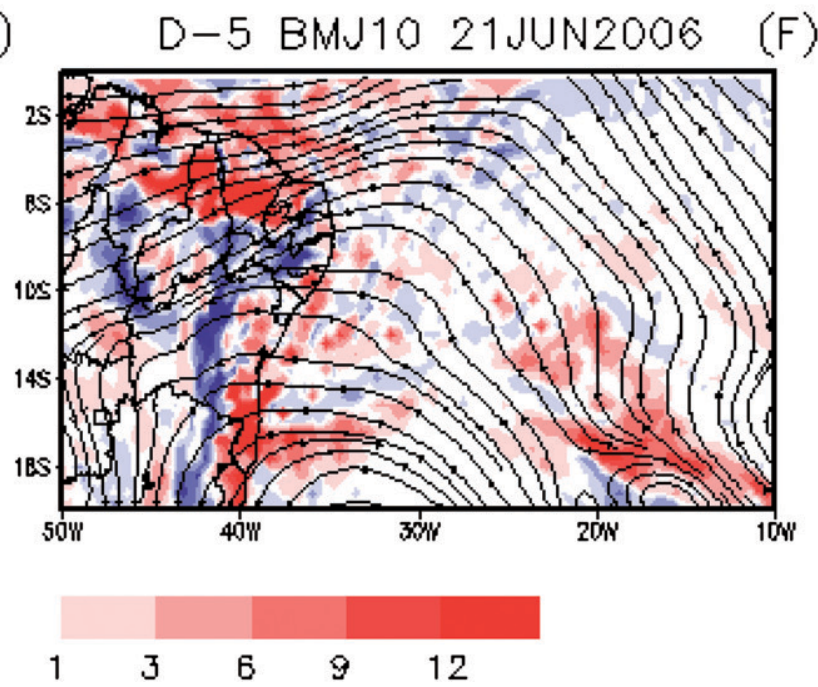

FIG. 7. As in Fig. 4, but for (a)-(f) the period from 16 to 21 Jun 2006 with an initialization time of 5 days before the 20 Jun 2006 event

Using all the Eta Model results, the following skill scores were computed: equitable threat score (ETS; Mesinger and Black 1992), bias score (Anthes et al. 1989) and probability of detection (POD; Baldwin and Kain
2006) (not shown). The rainfall thresholds used were the same as were utilized for the NCEP forecast evaluations. These evaluations indicate that better results were found for the smaller rainfall thresholds $(0.3 \mathrm{~mm})$, and 

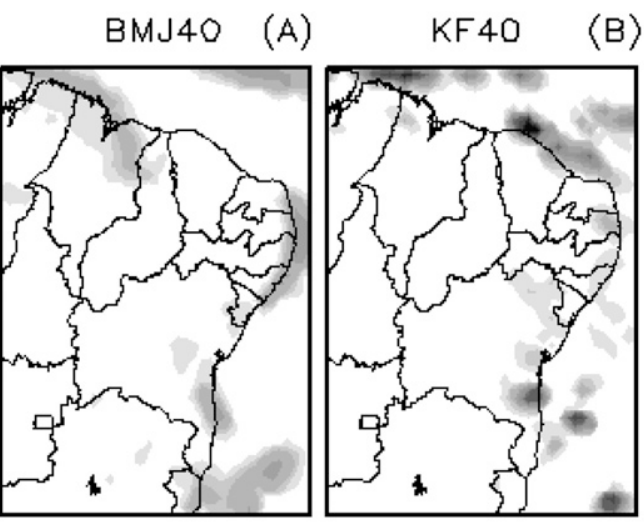

B)

BMJ10

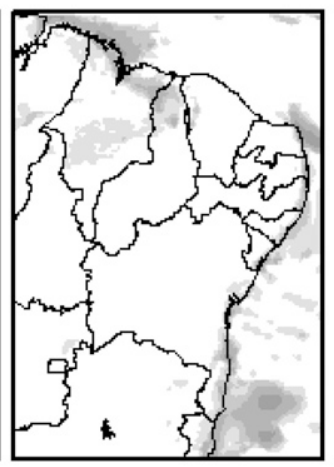

(G)
BM $10(\mathrm{H})$
(C)

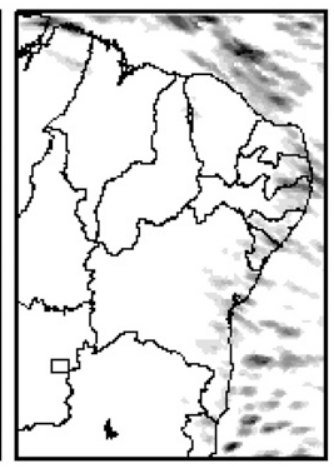

KF 10

(D)

(1)

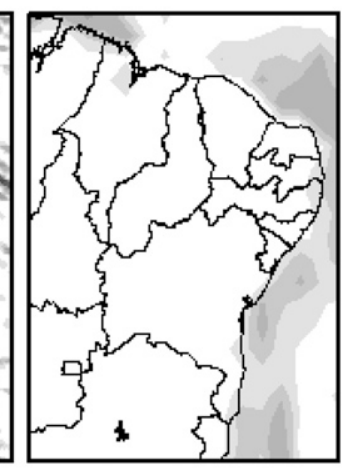

(d)
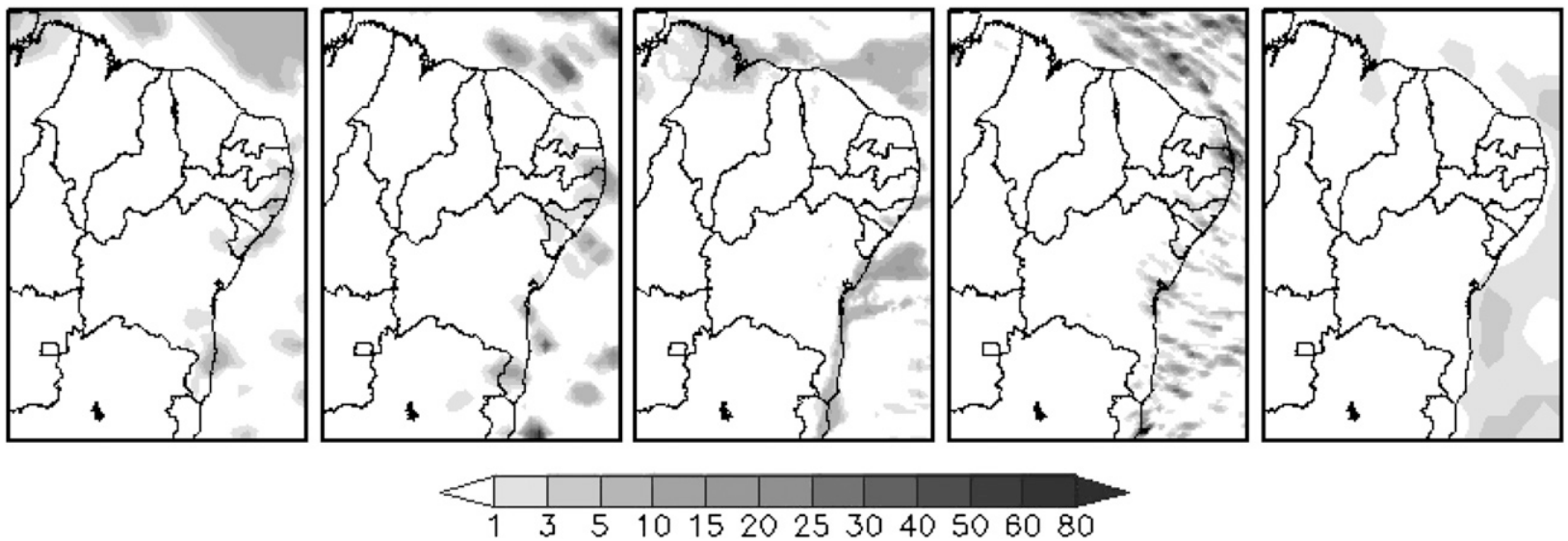

FIG. 8. Precipitation amount (mm) simulated by experiments with initialization times of (a)-(e) $2(D-2)$ and (f) $-(\mathrm{j}) 5$ days before $(D-5)$ the 15 May 2005 event. GFS model results are also included in (e) and (j).

performance decreased for higher thresholds. When analyzing the influence of two distinct Eta convective parameterizations, it was noted that experiments with the $\mathrm{KF}$ scheme present smaller errors and/or higher scores compared to experiments that used BMJ. Applying a statistical test to these results, none was significant at the $90 \%$ confidence level, which was expected given the small sample of simulations available.

Based on all simulations conducted in this study and for the two EWD events investigated, it was noted that the Eta Model did not significantly improve the rainfall prediction along the NEB east coast compared with a coarser-resolution global model.

\section{Concluding remarks}

In this study, the predictability of two EWDs that reached the east coast of NEB on 15 May 2005 and 20 June 2006 was evaluated through numerical simulations with the regional Eta Model. In these experiments, different horizontal resolutions and convective parameterization schemes were tested, with the aim of finding the most realistic configuration for forecasting this type of weather system. In the $700-\mathrm{hPa}$ wind fields, for both events simulated with the Eta Model, it was observed that experiments simulated well a trough propagating from east to west from about $20^{\circ} \mathrm{W}$ to the NEB coast with either 40- or 10-km spatial resolution and using either the BMJ or KF scheme. The results of both studied events suggest that the Eta Model simulates well this type of disturbance with a 5-day forecast range.

When evaluating the impacts of different convective parameterizations on rainfall simulations, it was verified that in general the experiments showed similar deviation fields relative to the observations. A predominance of regions with underestimations of rainfall was observed in all experiments.

In summary, neither parameterization employed in this study could be chosen as the most suitable for rainfall prediction related to EWD events in the NEB coastal region. Comparing the precipitation forecasts produced by the Eta Model and the GFS global model, no improvement was seen when using a high-resolution regional model to predict the rainfall associated with 

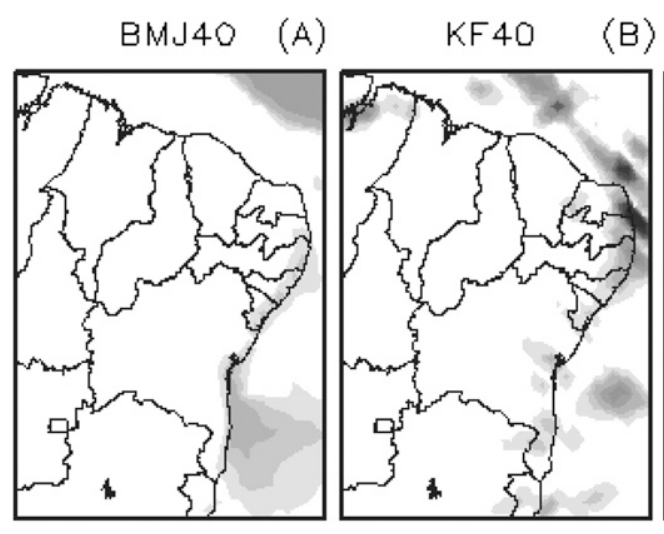

(F)

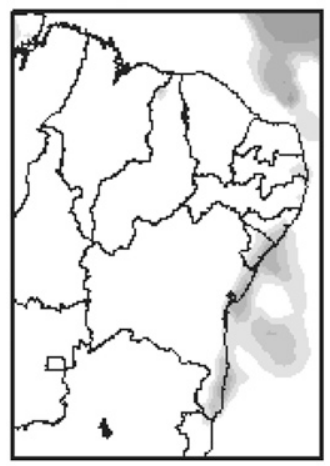

KF 40

(G)
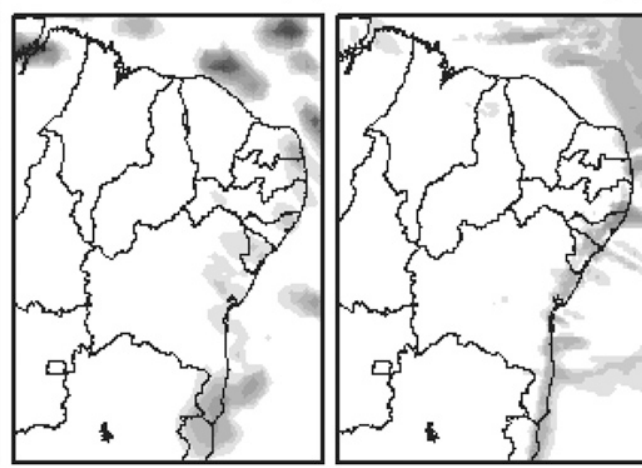

H)

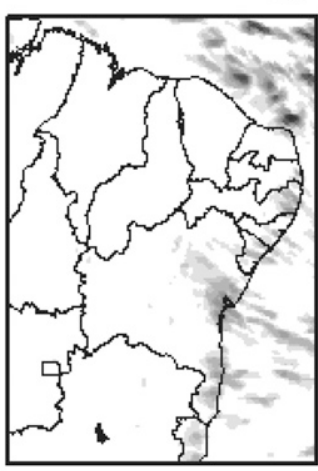

(1)

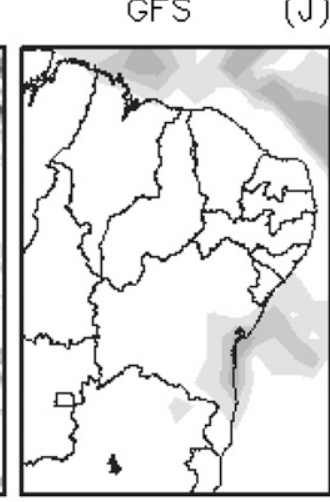

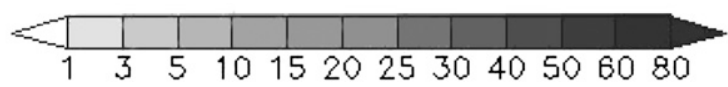

FIG. 9. As in Fig. 8, but for the 20 Jun 2006 event.

such events. The results presented in this paper are an attempt to evaluate the ability of the Eta Model to predict such important regional weather events, and the preliminary results emphasize the need to extend this analysis to a larger number of cases and to test and/or create other cumulus parameterizations schemes to improve rainfall forecasts in eastern NEB.

Acknowledgments. The authors were supported by the Brazilian National Council for Scientific and Technological Development (CNPq). We thank Jorge Luis Gomes, Gustavo Sueiro Medeiros, and José Roberto Rozante for their help with the Eta Model simulations. Thanks are also due to the anonymous reviewers for their relevant suggestions for the improvement of this work.

\section{REFERENCES}

Albignat, J. P., and R. J. Reed, 1980: The origin of African wave disturbances during phase III of GATE. Mon. Wea. Rev., 108, 1827-1839.

Anthes, R. A., Y. H. Kuo, E. Y. Hsie, S. Low-Nam, and T. W. Bettge, 1989: Estimation of skill and uncertainty in regional numerical models. Quart. J. Roy. Meteor. Soc., 115, 763-806.

Arakawa, A., and W. H. Schubert, 1974: Interaction of a cumulus ensemble with the large-scale environment, Part I. J. Atmos. Sci., 31, 674-704.

_ , and V. R. Lamb, 1977: Computational design of the basic dynamical processes of the UCLA general circulation model. Methods in Computational Physics, Vol. 17, Academic Press, 173-265.

Baldwin, M. E., and J. S. Kain, 2006: Sensitivity of several performance measures to displacement error, bias, and event frequency. Wea. Forecasting, 21, 636-648.

— - - and M. P. Kay, 2002: Properties of the convection scheme in NCEP's Eta Model that affect forecast sounding interpretation. Wea. Forecasting, 17, 1063-1079.

Berry, G., C. Thorncroft, and T. Hewson, 2007: African easterly waves during 2004-Analysis using objective techniques. Mon. Wea. Rev., 135, 1251-1267.

Betts, A. K., 1986: A new convective adjustment scheme. Part I: Observational and theoretical basis. Quart. J. Roy. Meteor. Soc., 112, 677-691.

_ Part II: Single column tests using GATE wave, BOMEX, ATEX and Arctic air-mass data sets. Quart. J. Roy. Meteor. Soc., 112, 693-709.

Black, T. L., 1994: The new NMC mesoscale Eta Model: Description and forecast examples. Wea. Forecasting, 9, 265-278. 
Chen, T. C., 2006: Characteristics of African easterly waves depicted by ECMWF reanalyses for 1991-2000. Mon. Wea. Rev., 134, 3539-3566.

Chou, S. C., J. F. Bustamante, and J. L. Gomes, 2005: Evaluation of Eta Model seasonal precipitation forecasts over South America. Nonlinear Processes Geophys., 12, 537-555.

Coutinho, E. C., and G. Fisch, 2007: Easterly wave disturbances over Centro de Lançamento de Alcântara-MA (in Portuguese). Braz. J. Meteor., 22, 193-203.

Ferreira, N. J., S. C. Chou, and S. Prakki, 1990: Analysis of easterly wave disturbances over South Equatorial Atlantic Ocean (in Portuguese). Proc. XIth Brazilian Congress of Meteorology, Salvador, Bahia, Brazil, CBMET, 10 pp. [Available online at http://www.cbmet.com/cbm-files/1866f87184b3a74625603a5cfb8345f5fe.pdf.]

Grell, G. A., 1993: Prognostic evaluation of assumptions used by cumulus parameterizations. Mon. Wea. Rev., 121, 764-787.

Hall, B. A., 1989: Westward-moving disturbances in the South Atlantic coinciding with heavy rainfall events at Ascension Island. Meteor. Mag., 118, 175-181.

Hastenrath, S., and L. Heller, 1977: Dynamics of climate hazards in northeast Brazil. Quart. J. Roy. Meteor. Soc., 103, 77-92.

Hsieh, J.-S., and K. H. Cook, 2005: Generation of African easterly wave disturbances: Relationship to the African easterly jet. Mon. Wea. Rev., 133, 1311-1327.

Janjić, Z. L., 1994: The step-mountain eta coordinate model: Further developments of the convection, viscous sublayer, and turbulence closure schemes. Mon. Wea. Rev., 122, 927-945.

Kain, J. S., 2004: The Kain-Fritsch convective parameterization: An update. J. Appl. Meteor., 43, 170-181.

_- and J. M. Fritsch, 1990: A one-dimensional entraining/ detraining plume model and its application in convective parameterization. J. Atmos. Sci., 47, 2784-2802.

_ , and - 1993: Convective parameterization for mesoscale models: The Kain-Fritsch scheme. The Representation of Cumulus Convection in Numerical Models, Meteor. Monogr., No. 46, Amer. Meteor. Soc., 165-170.

_-, M. E. Baldwin, P. R. Janish, and S. J. Weiss, 2001: Utilizing the Eta Model with two different convective parameterizations to predict convective initiation and evolution at the SPC. Preprints, Ninth Conf. on Mesoscale Processes, Fort Lauderdale, FL, Amer. Meteor. Soc., 91-95.

Kalnay, E., and Coauthors, 1996: The NCEP/NCAR 40-Year Reanalysis Project. Bull. Amer. Meteor. Soc., 77, 437-471.

—, M. Kanamitsu, and W. E. Baker, 1990: Global numerical weather prediction at the National Meteorological Center. Bull. Amer. Meteor. Soc., 71, 1410-1428.

Kanamitsu, M., 1989: Description of the NMC Global Data Assimilation and Forecast System. Wea. Forecasting, 4, 335-342.
- , and Coauthors, 1991: Recent changes implemented into the global forecast system at NMC. Wea. Forecasting, 6, 425-435.

Kayano, M. T., 2003: Low-level high-frequency modes in the tropical Atlantic and their relation to precipitation in the equatorial South America. Meteor. Atmos. Phys., 83, 263-276.

Kousky, V. E., 1979: Frontal influences on Northeast Brazil. Mon. Wea. Rev., 107, 1140-1153.

- , and P. S. Chu, 1978: Fluctuations in annual rainfall for Northeast Brazil. J. Meteor. Soc. Japan, 56, 457-465.

Mesinger, F., 1984: A blocking for representation of mountains in atmospheric models. Riv. Meteor. Aeronaut., 44, 195-202.

— , and T. L. Black, 1992: On the impact on forecast accuracy of the step-mountain (eta) vs. sigma coordinate. Meteor. Atmos. Phys., 50, 47-60.

_ Z. I. Janjić, S. Nickovic, D. Gavrilov, and D. G. Deaven, 1988: The step-mountain coordinate: Model description and performance for cases of Alpine lee cyclogenesis and for a case of Appalachian redevelopment. Mon. Wea. Rev., 116, 1493-1518.

Pan, H.-L., and W.-S. Wu, 1995: Implementing a mass flux convection parameterization package for the NMC MediumRange Forecast Model. NMC Office Note 409, 40 pp.

Paradis, D., J. P. Lafore, J. L. Redelsperger, and V. Balaji, 1995: African easterly waves and convection. Part I: Linear simulations. J. Atmos. Sci., 52, 1657-1679.

Rao, V. B., M. C. Lima, and S. H. Franchito, 1993: Seasonal and interannual variations of rainfall over eastern Northeast Brazil. J. Climate, 6, 1754-1763.

Reed, J. R., and E. E. Recker, 1971: Structure and properties of synoptic-scale wave disturbances in the equatorial western Pacific. J. Atmos. Sci., 28, 1117-1133.

Rozante, J. R., D. S. Moreira, L. G. G. de Gonçalves, and D. Vila, 2010: Combining TRMM and surface observation precipitation: Technique and validation over South American. Wea. Forecasting, 25, 885-894.

Strang, D. M. G. D., 1972: Climatological analysis of rainfall normals in Northeast Brazil. Centro Tecnológico Aeroespacial IAE-M 02/72, São José dos Campos, São Paulo, Brazil, 29 pp.

Thorncroft, C. D., 1995: An idealized study of African easterly waves. III: More realistic basic states. Quart. J. Roy. Meteor. Soc., 121, 1589-1614.

Yamazaki, Y., and V. B. Rao, 1977: Tropical cloudiness over the South Atlantic Ocean. J. Meteor. Soc. Japan, 55, 205-207.

Yanai, M., and T. Nita, 1967: Computation of vertical motion and vorticity budget in a Caribbean easterly wave. J. Meteor. Soc. Japan, 45, 445-466.

—_, T. Maruyama, T. Nita, and Y. Hayashi, 1968: Power spectra of large-scale disturbances over the tropical Pacific. J. Meteor. Soc. Japan, 46, 308-323. 
Copyright of Weather \& Forecasting is the property of American Meteorological Society and its content may not be copied or emailed to multiple sites or posted to a listserv without the copyright holder's express written permission. However, users may print, download, or email articles for individual use. 